\title{
Maintaining Climate Change Experiments: Urban Political Ecology and the Everyday Reconfiguration of Urban Infrastructure
}

\author{
VANESA CASTÁN BROTO and HARRIET BULKELEY
}

\begin{abstract}
Climate change governance is increasingly being conducted through urban climate change experiments, purposive interventions that seek to reconfigure urban sociotechnical systems to achieve low-carbon and resilient cities. In examining how experiments take effect, we suggest that we need to understand not only how they are made and assembled, but also how they are maintained within specific urban contexts. Drawing on literatures from urban political ecology and the specific debate on urban repair and maintenance, this article examines maintenance in two case studies of climate change experiments in housing in Bangalore (India) and Monterrey (Mexico). We find that maintenance is a crucial process through which not only urban obduracy is preserved, but also the novel and innovative character of the experiment is asserted and reproduced. The process of 'maintaining' experiments is a precarious one, which requires a continuous external input in terms of remaking the experiment materially and discursively. This process causes further reconfigurations beyond the experiment, changing the patterns of responsibility attribution and acceptability that configure the urban fabric.
\end{abstract}

\section{Introduction}

Addressing climate change in the city requires an engagement with the urban infrastructure systems that mediate the production and consumption of energy and greenhouse gas emissions, and which shape urban vulnerability to the impacts of climate change (Monstadt 2009; Hodson and Marvin 2011). While analyses of urban climate change responses have typically focused on the policy sphere and the development of plans and strategies to address the issue, acknowledging that urban infrastructure, understood as the sociotechnical matrix that facilitates the provision of services needed for urban life, is critical to any urban response opens up the possibilities for looking elsewhere in the city at how climate change is being addressed. Seen in this way, the plethora of seemingly one-off or ad hoc interventions — including behaviour-changing

We are grateful to Diane Diacon and Steven Graham for their feedback and support shown during the development of this article. We would also like to thank three anonymous IJURR reviewers for their comments. The research undertaken in preparing this article has been supported by Harriet Bulkeley's ESRC Climate Change Fellowship (2008-2012) 'Urban transitions: climate change, global cities and the transformation of socio-technical networks' (award no. RES-066-27-0002). The usual disclaimers apply. 
policies, development of new energy sources and new systems of water delivery, transport and waste collection - are part of the growing urban response to the challenges of climate change.

Some such interventions, which we term 'climate change experiments' (Castán Broto and Bulkeley, 2013), are purposively designed to trial the social and technical experience of responding to climate change, put new materials, technologies and social actions to the test, or develop knowledge within the city to respond to climate change. In the context of uncertainty, urban climate change interventions become experiments, or projects in the making, in the sense that they are used to explore uncharted policy territories, to either learn or open up new forms of intervention, and often without consideration of their unintended consequences. Understanding how such experiments take effect becomes a critical means to explain urban responses to climate change, because "experiments serve to create new forms of political space within the city, as public and private authority blur, and are primarily enacted through forms of technical intervention in infrastructure networks, drawing attention to the importance of such sites in urban climate politics' (Bulkeley and Castán Broto, 2013). Moreover, as specific interventions in infrastructure networks, experiments challenge current understandings of urban responses to climate change and, more fundamentally, the conceptualization of the dynamics of such networks.

In this article, we interrogate one particular aspect of this process - maintaining experiments - more closely. Maintenance emerges as a key aspect of urban climate change experimentation, as a means to manage its inherent uncertainty. To theorize experiment maintenance we adopt the following strategy: in the first part of the article, we draw on literatures from urban political ecology concerned with the processes of metabolic circulation (Gandy, 2004; Kaika, 2005; Keil, 2005b; Heynen et al., 2006; Swyngedouw, 2006; Monstadt, 2009) and from urban geography on the process of 'repair and maintenance' (Thrift, 2005; Graham and Thrift, 2007; Strebel, 2011) to suggest that this is at once a strategic, political process, and one shaped through the experiences and practices of everyday urbanism. Conceptualizing maintenance in this dual fashion allows us to examine the ways in which climate change experiments become embedded within and serve to reconfigure forms of urban metabolism. In the second part of the article, we adopt a comparative approach as a critical strategy for creative learning (Robinson, 2006; McFarlane, 2010) about the materialization of climate change discourses in different urban settings. Urban climate change experimentation involves the transposition of best practice examples or models across cities (for examples, see Bulkeley, 2010). As 'policies in motion' (Ward, 2006), climate change experiments adjust to and reconfigure the settings in which they are deployed, in this case, two case studies in the housing sector in Bangalore (India) and Monterrey (Mexico).

The theoretical framework is mobilized to understand how urban climate change experiments are maintained or otherwise within the infrastructure fabric of the city. We find that this is not achieved through rendering infrastructures as 'invisible', as much of the writing on urban infrastructure suggests (e.g. Star, 1999), but rather requires an explicit and ongoing work of maintenance to integrate and assert the experiment within particular urban contexts. These processes we describe as 'metabolic adjustment', involving the connection and disconnection of urban flows, and 'upkeep', consisting of multiple urban practices leading to new infrastructure configurations. They constitute a key aspect through which the innovative character of experiments is sustained and reworked, while also ensuring that they become accepted. We argue that such processes are critical to understand the effect of experiments within the context of urban development in which they emerge.

\section{Urban infrastructures and the maintenance of urban life}

Scholarship in urban political ecology has drawn attention to the ways in which the conditions of urban life are structurally produced and maintained through the continual circulation of capital, resources and nature (e.g. Swyngedouw and Heynen, 2003; 
Keil, 2005a; Heynen et al., 2006; Monstadt, 2009; Cooke and Lewis, 2010). Flows of 'metabolic circulation' are central to the realization of the urban condition because they enable the exploitation of natural resources and, in turn, produce the 'enabling and disabling social and environmental conditions' of the city (Monstadt, 2009: 10; see also Heynen et al., 2006; Swyngedouw, 2006). Urban political ecology analyses demonstrate that the transformation of ecological systems into the city is vital because 'urban politics has fundamentally to be about modes of transformation of nature related dialectically to modes of self-realization of a particular form of human nature' (Harvey, 1996: 435). This transformation is orchestrated through policies and interventions that require the ordering of urban natures, to separate 'good' and 'bad' natures according to socially constructed understandings of what the city ought to be (Desfor and Keil, 2004; Kaika, 2005).

Infrastructure networks are seen as central to these processes of transformation, as the 'functional lattice' through which material flows and flows of power are mediated (Gandy, 2004). Infrastructure, as a sociotechnical configuration, is produced by these circulations and the means through which urban metabolism takes place. Circulation is inherent to the processes whereby wider circuits of capital and politics structure urban metabolisms and confer stability to the city. Through these processes of circulation and flow the apparent permanence and fixity of urban forms and governance is conferred (Harvey, 1996) and networks are rendered invisible (Star, 1999). This obduracy can be understood as caused by the embeddedness of different elements in closely interrelated assemblages of socially constructed and technically produced elements (Hommels, 2005 , 2008). At the same time, these processes are dynamic, emergent and unruly, involving both the continual reproduction of urban conditions and an inherent unpredictability. Maintaining urban infrastructure can be seen in this view as a broadly structural process of achieving or containing particular forms of metabolic circulation orchestrated by forms of connection, disconnection and fragmentation. Through this process infrastructure networks are simultaneously challenged and invested with obduracy to ensure the dual production of nature and capital circulations within the city. In this manner, maintenance becomes critical to the reproduction of the material/ infrastructure in everyday life, and to its continuing structuring effects in the city.

As specific interventions in infrastructure networks, and in line with the broad literature on urban political ecology, experiments require a reworking of the flows of power, resources and materials through which infrastructure systems are sustained. Achieving this intervention, we argue, requires a process of 'metabolic adjustment' through which experiments may be embedded within particular circulations and reconfigure the infrastructural 'lattice' of the city. As a form of metabolic adjustment, maintenance processes sustain and redirect metabolic flows and become a critical means through which the reconfiguration of infrastructure networks takes place. Maintaining experiments can therefore be regarded as a process in which new rationales of nature and space production come to the fore.

However, maintenance is a structural process concerned with broad circuits and systems. As Graham and Thrift (2007) argued, everyday practices in the city also play a critical role in the (often hidden) processes of repair and maintenance, which constitute the 'urban technological unconscious which helps to keep cities as predictable objects in which things turn up as they are meant to, regularly and predictably' (Thrift, 2005: 136). Graham and Thrift (2007: 4) position these processes as 'reality's bridge' between the 'ready-to-hand', taken-for-granted world of practical action and the visible disruption to the everyday life of failed things. Here, maintenance is understood as the practical, microscale means through which urban networks are kept in 'good repair', and in turn, through which particular sociotechnical configurations are sustained. This 'carpet of ongoing maintenance and repair' present in every city is characterized by five qualities: its reliance on the power of things; the pluricultural character of things, whereby 'they have come to play a role in the everyday life of almost everyone'; the growing demand for maintenance and repair created by the growing number of things and their complex material composition; the imperative created by the growing reliance on infrastructure 
networks for urban life to ensure decay and disruption is minimal; and increasing difficulty to "define what the "thing" is that is being maintained and repaired' between objects, social relations and ways of urban living (Graham and Thrift 2007: 3-4).

This work specifically points to the range of mundane and intricate practices involved in maintenance, from street cleaning to the relaying of gas pipes. Everyday life is orchestrated through and around these activities, so that 'modern urban dwellers are surrounded by the hum of continuous repair and maintenance' (Thrift 2005: 136). In these readings, repair and maintenance are positioned, on the one hand, as a means through which the elemental decay of urban life is held at bay, constituting a critical part of urban (political) economy, and we would add, ecology; and, on the other hand, such processes are also regarded as central to the creation of new forms of urban life, as 'a vital source of variation, improvisation and innovation' (Graham and Thrift, 2007: 6). In this view, experimentation emerges in the process of maintenance for: "when things break down, new solutions may be invented ... there is some evidence to suggest that this kind of piece-by-piece adaptation is a leading cause of innovation, acting as a continuous feedback loop of experimentation which, through many small increments in practical knowledge, can produce large changes. Seen in this light, "maintenance is learning" ' (Brand, 1994: 127, quoted in Graham and Thrift, 2007: 5). Graham and Thrift demonstrate the ways in which maintenance is critical not only in reproducing forms of urban obduracy but also in facilitating urban transformations. Developing this argument, we suggest, entails understanding that the maintenance of change ${ }^{1}$ is as significant as that of stasis or decay, and in itself creates a powerful force of urban permanence/immanence.

Graham and Thrift's seminal work on repair and maintenance provides a critical means through which to understand the mundane and practical ways in which the upkeep of infrastructure networks serves to continually reproduce the urban landscape. Yet, we find that maintenance is not limited to the upkeep of existing assemblages, but is central to the work of experimentation itself. This is because maintenance is about sustaining the existence of current sociotechnical relations or of keeping things in 'good repair' (anticipating failure, disruption or decay), and it is a means through which experiments are offered support and affirmation as they become normalized within particular urban contexts. As a set of mundane practices, maintenance can therefore be regarded as a means through which experiments are sustained and gain 'momentum' in the city. In other words, 'maintenance is not only an event through which relational assemblages of human and nonhumans are brought into view, but a course of action in which [in this case] the high-rise [building] gains momentum' as a 'living' entity (Strebel, 2011: 248). Furthermore, while Graham and Thrift focus on the micropractices and everyday nature of maintenance, drawing on the urban political ecology perspective above, we also suggest that this process is central to the reproduction of power and discourses that enable certain forms of metabolic circulation to become viewed as normal and embedded within the city.

Reading across these literatures from urban political ecology and urban geography, maintenance emerges as a set of processes that are, on the one hand, concerned with the strategic and structural dynamics of sustaining and reworking particular forms of metabolic circulation and, on the other, undertaken through a range of mundane and everyday practices (Table 1). As disruptive interventions within the infrastructural lattice' of particular urban contexts, we suggested that climate change experiments give rise to maintenance practices that reveal their critical role in the dynamic transformation of urban landscapes in response, in this case, to the climate change problematic. We identify here the potential for 'metabolic adjustment', as the experimental intervention reconfigures network flows and the micropractices involved in the 'upkeep' of

1 In the context of climate change, urban change is understood as a 'transition' to a low-carbon society, that is, as a fundamental change in the way a service is delivered. 
Table 1 Representation of maintenance as a dual process of metabolic adjustment and upkeep

\begin{tabular}{|c|c|c|c|}
\hline & \multicolumn{2}{|c|}{ Dual function } \\
\hline & & Permanence & Change \\
\hline \multirow[t]{2}{*}{$\begin{array}{l}\text { Form of } \\
\text { maintenance }\end{array}$} & Metabolic adjustment & $\begin{array}{l}\text { Embedding the experiment } \\
\text { within the existing urban } \\
\text { metabolic circulations }\end{array}$ & $\begin{array}{l}\text { Resignifying the experiment } \\
\text { as a symbol of structural } \\
\text { reconfigurations }\end{array}$ \\
\hline & Upkeep & $\begin{array}{l}\text { Normalizing the experiment } \\
\text { in everyday practices }\end{array}$ & $\begin{array}{l}\text { Asserting the experiment as } \\
\text { a process in the making }\end{array}$ \\
\hline
\end{tabular}

experiments. Upkeep and metabolic adjustment processes have a dual function in the sense that they are simultaneously directed towards ensuring the permanence of the experiment within the given infrastructure context, and asserting its potential for provoking change. Thus, as demonstrated below, we find that maintenance is required to sustain the novelty of experiments and to normalize them within particular urban contexts.

\section{Maintaining climate change experiments in Mexico and India}

Climate change experiments, as explicit interventions in urban infrastructure systems that seek to reconfigure sociotechnical relations around climate change, provide a critical and intriguing site through which to further explore how forms of maintenance contribute to the reproduction and reconfiguration of urban landscapes. We selected, from a database of 627 urban climate change experiments, two cases on housing that were recognized as having a systemic impact in the city in which they occur.

The first case study is a gated development of 91 eco-homes for high-income professionals in the urban periphery of Bangalore (India) called Towards Zero-Carbon Development (T-Zed), led by a private developer called Biodiversity Conservation India Ltd (BCIL). The second case study is a social-housing development of 51 houses in Monterrey (Mexico) called Vivienda de Diseño Ambiental (ViDA), led by the state-based housing institute (Instituto de la Vivienda de Nuevo Leon) and supported by the National Housing Commission (CONAVI) with the collaboration of Infonavit, a federal institute that provides mortgages for workers' housing. Fieldwork was carried out during 3 weeks in Bangalore (March 2010) and Monterrey (April-May 2010). The fieldwork consisted of visits to the sites and interviews with key actors who had intervened in the development directly or indirectly. There were 47 interviews in Bangalore and 31 in Monterrey. In Bangalore interviewees included key actors in T-Zed (14 interviews, 1 informal), residents (6 interviews) and other actors influencing local climate change governance, including NGOs, public sector officials and academics (33 interviews, 5 informal). In Monterrey interviewees included key actors in ViDA (11 interviews, 4 informal), residents (7 interviews, 3 informal) and other actors influencing local climate change governance, including NGOs, public sector officials and academics (13 interviews, 1 informal). Formal interviews were conducted in a formal setting, with an interview guide, and they were taped, transcribed and coded using a predetermined coding guide. In some cases (indicated above) only informal meetings were possible due to time or personal constraints. The analysis also examined a range of written sources including promotional materials, government press releases, newspaper articles, discussion articles in architectural blogs and forums and academic presentations. Table 2 summarizes some of the main characteristics of each development. In both cases, the housing developments challenge established sociotechnical arrangements within the housing system in an effort to address climate change. 
Table 2 Main characteristics of experiments

\begin{tabular}{lll} 
Name of experiment & T-Zed & ViDA \\
\hline Experiment led by & $\begin{array}{l}\text { Biodiversity Conservation India } \\
\text { Ltd (BCIL) }\end{array}$ & $\begin{array}{l}\text { Instituto de la Vivienda de } \\
\text { Nuevo León }\end{array}$ \\
\hline Lead organization & Private & Public \\
\hline Assembling resources & $\begin{array}{l}\text { Commoditization/product } \\
\text { making }\end{array}$ & $\begin{array}{l}\text { Public provision of social } \\
\text { housing }\end{array}$ \\
\hline Infrastructure provision & Developer & Developer \\
\hline Completion date & 2007 & 2008 \\
\hline Main innovations & $\begin{array}{l}\text { Carrying capacity design, } \\
\text { traditional construction } \\
\text { techniques, biodigester, } \\
\text { community living }\end{array}$ & $\begin{array}{l}\text { Design adapted to climate: } \\
\text { orientation, ventilation, } \\
\text { energy-efficient appliances }\end{array}$ \\
\hline
\end{tabular}

Whereas, broadly, T-Zed and ViDA attempted to develop low-carbon models of urban development in their cities, their objectives could not be more different. T-Zed focuses on creating alternative markets for green developments while ViDA attempts the seamless integration of low-carbon development principles in an existing and well developed social housing industry. Their comparison sheds some light on the mutual relationship between experimentation and urban maintenance. In line with the theoretical discussion above, and following the analysis summarized in Table 1, we identify maintenance as consisting of two related components. First, we focus on the ways in which the experimental quality of these infrastructural interventions requires forms of everyday upkeep. Second, we articulate how maintenance as 'metabolic adjustment' takes place to redirect urban circulations around and through the experiment as an exceptional space, and to embed them in the specific sociotechnical arrangements of the city and neighbourhood. We argue that this form of maintenance involves the need to preserve the innovative character of the experiment and a process of normalizing the experiment so that it can be integrated within existing urban practices. This may require reframing the experiment to adapt to the specific discursive mechanisms seeking its reproduction at other scales. Through each form of maintenance, we find that there is a tension between the need for standardization of the experiment or experiment components, and the need to re-experiment the intervention to highlight its exceptionality and further its momentum.

\section{The everyday upkeep of experiments: novelty and normalization}

Upkeep is a form of maintenance, which occurs in everyday practices. How upkeep occurs is tied to the design of the experiment and to the constellation of actors intervening and the urban infrastructure regime in which it is deployed. In T-Zed, BCIL see themselves as 'helping people to get some sense in the decisions they make' (interview $\mathrm{T}$-Zed $\mathrm{D}^{2}$ ), that is, to help high-income middle-class professionals to combine green aspirations (global and local) with housing aspirations (big houses with modern commodities and secure supply of energy, water and waste). In ViDA, the project was made possible by promoters from the Instituto de la Vivienda de Nuevo Leon and CONAVI who kept in mind not the interests of future residents (who were thought to

2 Throughout the article the interviews have been designated by a letter (developers $\mathrm{D}$; consultants and knowledge producers $\mathrm{C}$; residents $\mathrm{R}$; public sector workers $\mathrm{P}$; and NGOs N) and a number. 
benefit indirectly from the project) but those of developers, who should be able to implement eco-technologies without increasing their costs.

Regarding urban infrastructure regimes, the landscape of Bangalore is one of fragmentation where multiple services for service provision coexist. In terms of water, waste and energy, the city is provided through various governance arrangements which combine public provision in networked areas (mostly old quarters of the city) and private arrangements for high-income classes in new developments and for the poorest sectors of society which live in new layouts outside the main networks or in informal settlements (e.g. Ghosh, 2005; Ranganathan et al., 2009). Differences in governance arrangements of service provision have led to a spatial fragmentation of services - a splintering whereby upcoming areas are able to securitize privately the provision of water and other services in gated communities (see Graham and Marvin, 2001). In Monterrey, permits for development are given under the condition that developers lay down the corresponding infrastructure according to municipal regulations (although regulations vary in each municipal term, leading to coordination problems). Municipal authorities take up responsibility for service provision after the development is complete, but they cannot always meet these because of challenges related to rapid growth and resource availability, particularly in terms of water provision and availability of land for construction with continuous struggles over the development pressures on the natural resources of the city.

The result is two differentiated forms of maintenance as upkeep. In T-Zed, we find a privatized form of maintenance, customer oriented, whereby BCIL is in charge of the everyday management of the site. According to the onsite manager, this is because the site requires 'special care that only BCIL can provide' (interview T-Zed D1). However, maintenance is also regarded as a failure to deliver the experiment in time: 'Construction was still going on two months back' (interview T-Zed R2), explained one resident in March 2010, having lived for 3 years on the compound. For some, this signifies a prioritization of environmental protection aspirations over delivery: 'because things are not finished ... there are like levels and there are rough edges where you can hurt yourself . . . it seemed to me: "okay, you are trying to do all the environmental stuff but you are not really taking care of the people who are here" ' (interview T-Zed R4). Upkeep practices, here, are directed towards re-experimentation rather than normalization.

In ViDA, in contrast, the project was constructed and delivered in time. In the context of security of demand from workers guaranteed by Infonavit, developers are able to design highly standardized house types in which the use of materials is typified to minimize the costs of integration and transformation of materials available from suppliers. Thus, the architects from the Instituto de la Vivienda developed a design, which integrated bioclimatic construction principles while minimizing deviations from existing types. A representative of the Instituto de la Vivienda explained that they 'took a typical house prototype, broke that into pieces and put it together so that it had some [green] features' (interview ViDA P1). The architect responsible for the project explained that the pressure came from developers who told them "not to move anything ... so we looked at the window, for example, not to change it but just to consider its orientation ... because when you make a project you need to understand the developers' (interview ViDA C1). Bioclimatic modifications had an additional cost, which was covered by the Instituto de la Vivienda providing land at a reduced price to facilitate the developers' financing. Overall, the houses were built according to plan, without challenging any standard procedures within the housing industry.

On completion, ViDA's houses were delivered to residents who would have to take care of the maintenance of each independent unit. With respect to the houses, residents explained that, beyond a few months' guarantee, the developer breaks any relationship with the development on completion. This is a common feature of housing developments under Infonavit. 'At this moment, we are not able to follow-up developments once they are completed', lamented an Infonavit representative (interview ViDA P3). As in other developments, a representative of the municipal department for public services explained 
that 'developers provide the pavement, street furniture, street lighting and other infrastructures [costs are included in the price of the house] and we confirm that they meet our specifications before taking the responsibility for the maintenance of services' (interview ViDA P2). However, as a representative of the local community explains, the community receives only limited support and it needs to take charge to ensure provision actually occurs. For example, a resident explained that in their relation with municipal services personnel 'the community needs to mark them the way and you have to be asking them continually whether they come or not' (interview ViDA R2). Ultimately, the maintenance of the development (not only of individual houses but also of common spaces such as the pavements and the park) is left in the hands of residents.

These cases demonstrate two fundamentally different models of upkeep. The TZed model relates to the involvement of the developer and the splintering urban configuration, which promotes private and customer-led patterns of service provision met collectively by the developer. In contrast, in ViDA, upkeep needs are determined by the developers' demands within the well-established conglomerate of the construction industry, finance and government, which effectively assumes maintenance to be outsourced to the municipality and the residents. Whether maintenance is regarded as a continuation of the experiment-making process (such as in T-Zed) or as a finished product (such as in ViDA) determines the upkeep protocols, regardless of residents' concerns (which in both cases complained about certain standard and operations, as explained below).

These different modes of governance also create material differences in the life of the experiment, in terms of individual dwellings, common spaces and the development as a whole. T-Zed, despite the signs of ongoing construction work (the rubble on one of the sides of the entrance; the sounds of construction work going on in some of the flats which had to be refitted; the barren piece of land which cannot be landscaped because its ownership is disputed), is perceived as a coherent whole. The house units in T-Zed are connected by gangways and gardens. Common units (a restaurant, pool, paddle, gardens and activity rooms) are extensions of collective spaces shared between houses, rather than additions. In ViDA, in contrast, there is no apparent connectivity between the houses. Residents explained that they felt they cannot use the collective areas freely (including front gardens, pavements and playground areas) because of safety fears. They also said that, apart from isolated efforts from some groups of residents, nobody maintains these common areas.

ViDA architects highlighted that, as an experimental project, some features of the project did not work as they expected. However, residents do not express concerns about the maintenance of individual households (although they may have adapted different elements to suit their needs). They compare their houses with similar alternatives, pointing at differences in terms of size and location. The 'bioclimatic' character of the houses is somehow eroded. Even the community elected representative (the 'juez'), when prompted, said that if the house was bioclimatic 'that must have been because of the solar panel used to light the three bulbs outside' (interview ViDA R3), a feature which was incorporated only later in the design. Orientation, ventilation and other features of the house concern residents when they feel their negative consequences (for example, when strong winds cause dusting within the houses). Attempts to re-experiment the development, through a survey in 2010 about how residents were using the houses and parallel education campaigns, appear to have a minimal impact on the material operation of the housing development and on local residents' views.

T-Zed residents also compare the standards in their houses with those of developments for similar income bands. From this comparison, residents infer that the incorporation of multiple design and technological innovations have resulted in unexpected additional maintenance issues. Roof gardens leaked, unconventional construction materials did not provide the services expected, natural stones for tailing deteriorated faster than predicted: the whole development is a life project, still in the making. A BCIL customer-service worker explains some of these problems: 'initially we had dampness . . in the walls ... 
the customers had painted them in their own way and then we found bubbles in the paint, because the paint was not absorbed properly; then plumbing, then power problems, but [these are] normal maintenance issues, there is not anything specific for T-Zed' (interview T-Zed D6). What for BCIL are 'normal maintenance issues' for some residents is a cause for dissatisfaction and concern. As Graham and Thrift (2007: 4) argue 'accidents that stem from so many breakdowns are not aberrant but are a part of the thing itself'. Experimentation is inherently more prone to decay. Both in ViDA and T-Zed, maintenance is closely related to the power of things. However, while in ViDA, maintenance becomes embedded in residents' everyday practices of material production, in T-Zed normalization is led by the developer and maintenance becomes a process of expectations management.

The result is that BCIL's presence in T-Zed is needed to respond to the continuous demands of residents. In some cases, this has led to a renegotiation of the original terms, including refitting and alternative solutions for unsatisfactory technologies. In other cases, it has prompted a relaxation of BCIL's demands on residents about what appliances are allowed in the compound. For example, BCIL envisaged that, to reduce the consumption of energy, flats and houses would be provided with customized appliances for air conditioning and refrigeration. The fridges now pile in BCIL offices, as residents rejected the models (some found them too small and others simply could not get them to work) and there are ongoing discussions about whether the fridges were ever operative. After some disputes, residents are now 'free' to buy their own cooling appliances. Refrigeration was described by a consultant as one of T-Zed's major failures, and the system has been abandoned in new BCIL projects. Overall, BCIL confronts in T-Zed a proliferation of things being maintained and imperative demands for BCIL to provide immediate responses to each crisis. Even aesthetic issues provoke questions regarding the residents' lifestyles and exhibit, as Graham and Thrift (2007) highlight, 'an existential quality'.

These two contrasting models of upkeep, in relation to the actors involved in the experiment, reveal some of the fundamental features of maintenance. In both cases, the experiment has a life beyond assemblage, so that its elements need to be adjusted to deal with multiple changing relations through scrubbing, adapting, cleaning and reinventing as maintenance demands proliferate. This process will determine the eventual reassertion of the experimental character of the initiative. The proactive role of BCIL in T-Zed confers purpose to the experiment and reasserts innovations at the expense of compromising its normalization: continuous re-experimentation becomes a source of anxiety among residents. In ViDA, the lack of purposive maintenance gives way to conventional forms of repair and as a result becomes integrated in the landscape so that its potential ebbs away, despite architects' attempts at re-experimentation through surveys and education campaigns.

\section{Metabolic adjustment: embedding and reframing experiments within urban flows}

Metabolic adjustment refers to a series of discursive and spatial processes that are needed to adjust the experiment to the conditions of urban development in which it emerges, while resignifying the experiment as a symbol of the intended structural configurations. Again, we find this is a dual process, which attempts to gain stability and assert the exceptionality of the experiment within the specific conditions in which it emerges. The comparative analysis of the cases of T-Zed and ViDA suggests that permanence and change are embedded in the experiment design but require maintenance in terms of asserting such designs through time and space. The key aspect common to both experiments is their emphasis on resource securitization (securing water resources, energy but also land and space), a feature that shapes how they unfold over time. 
The most fundamental difference between T-Zed and ViDA is that they are targeted at different consumer groups: T-Zed is a gated compound for high-income professionals while ViDA is a social housing project for salaried workers. Each one represents the dominant trend in their respective cities. Following the unprecedented growth during the last two decades in Bangalore, new developments have been constructed to host big complexes of offices and residences for a rapidly growing class of middle and high-income professionals. In Monterrey, urban sprawl has occurred in a polycentric manner, with massive social housing developments organized in 'villages' and often centred on a particular industry, as is the case of the municipal term of Escobedo, in the conurbated area of Monterrey, where ViDA is located. What is common in both cases is that low-carbon experimentation in housing fails to challenge the accelerated process of urban sprawl. While T-Zed is oriented towards selling a suburban dream house to those who can afford it, ViDA is an example of how social housing contributes to the process of urban expansion in Mexican cities.

Moreover, neither example challenges fundamentally the housing industry or its drivers. In Bangalore, the construction industry is lured by the demands for space and comfort of the professional classes. Being mobile and cosmopolitan, this new class of customers demands a standard of service - from air conditioning to swimming pools which is alien to the traditional city (Nair, 2000). While T-Zed designers advocate the use of local materials and sustainable technologies, they conform to imported models of suburban development. T-Zed is not different from nearby developments in that it seeks to enrol high-income customers with a premium product - characterized for being 'green' - in a gated community alongside one of the industry corridors in the outskirts of Bangalore. In Monterrey, like in the whole of Mexico, most social housing is financed by Infonavit, a public-private financial institution that has given more than 5 million mortgages to salaried workers since its creation in 1972. Infonavit is associated with a strong industry of housing development described by a local architect in an interview as 'a goose that lays homes' (interview ViDA, C1). This industry (consisting of a multitude of big and small private developers) has developed house types to make house units as cheap as possible, so that they can meet the requirements of social housing mortgages at Infonavit. The result is the perpetuation of repetitive models of construction in cheap land and an aversion to innovation, which has led to the exponential rise of urban sprawl in most Mexican cities. The integration of both experiments in the dynamics of urban development - in terms of form and design - exemplifies the permanence function of maintenance already embedded in the experiment's design.

However, this is not a smooth process, precisely because, as highlighted in the urban political ecology literature, the integration of the experiment with its surrounding environment depends on the infrastructure connections with the rest of the city. In T-Zed, the idea of a self-sufficient home, advanced here under a carbon reduction flag, contributes, on one hand, to create a luxury development in the context of lack of infrastructure for that type of service provision and, on the other, to securitize resources in the light of a future resource crisis that is affecting the whole city, particularly regarding water and energy. Self-sufficiency is also regarded as a benefit to the whole city: "we are saving the cost of the entire society by lowering the load of what we are taking in electricity from the grid and by not connecting to the municipal sources' (interview T-Zed D2). This discourse emphasizes the type of private service provision characteristic of this kind of developments. Ultimately, private provision is here a strategy for resource securitization (Hodson and Marvin, 2009), which eventually leads to the splintering of infrastructures, such as in this case, water (Graham and Marvin, 2001).

In contrast, the relationship of ViDA with its surrounding environment is mediated by the residents' reactions to the context of violence in Monterrey. Fragmentation here happens from household to household as individual families try to securitize their home. Ideas of sustainability and green communities vanish in the face of rampant social violence (which has increased dramatically in Monterrey during the last decade 
associated with the growing interest of the drug cartels in the Monterrey 'plaza'). Violence encroaches in the daily life of residents: 'there is a lot of gang violence ... you can see it here, in this development ... not inside, inside there is not a lot but around ... but I am here in the limiting area and I can see ... they fight, they break the house ... so we built a bit in the entrance, like a defense' (interview ViDA R4). Residents feel safe regarding the neighbours in the development, but still feel pressure to securitize their individual houses. This is done by building fences and annexes around the house, which protect the main living areas. Rather than using the collective playground, children play in front gardens now fenced up for each individual house. Also, as houses have become integrated in the neighbourhood lives and economies, they have been modified to provide security enclosures and by adding self-assembled structures to enable householdbased commercial activities which are common in this type of settlement. The original designs - suited to the specific climatic conditions of the settlement — have also been modified by the integration of the development in the economic landscape.

Resource and land securitization, however, occurs only through a set of reconnections. In Bangalore, BCIL claims that T-Zed is a pioneering development which does not depend on municipal water supply thanks to an innovative design focused on rainwater harvesting. However, an unplanned long drought resulted in the system not being able to recharge itself as planned. Thus, BCIL built two bore wells in T-Zed at high depth, in the manner that privileged classes are already doing in other parts of the city. This allows the development to remain independent from the municipal piped supply but encroaches on collective groundwater resources. The original concept of maintaining the compound exclusively with rainwater harvesting had to be rethought: 'We have local water ... we had to go and dig a few wells and withdraw the water, okay, that's a need out there. But water, water falls on to this piece of land ... We make sure water that is harvested back out there' (interview T-Zed D1). Water harvesting is still done to complement the main supply, but the supply of water relies heavily on the existence of bore wells extracting from the collective water table in Bangalore (to which poorer sectors of society have no access). Moreover, this creates further tensions with people living in the surrounding areas. One T-Zed resident explained that:

every morning there is a long line outside the gate, of people who want to . . collect water, take water from T-Zed for drinking! ... they don't have any drinking water! ... And ... the Association [of residents] doesn't approve of it! . . because they don't know how many ... once you start, you really can't stop! But, I think the security allows a lot of people in because either they pay [or] they empathise with them (interview T-Zed R4).

Residents have anxieties about what they perceive as an illegitimate use of the water resources they have securitized. However, the fundamental issue about T-Zed appropriating collective water resources and restricting access to other citizens is not discussed. T-Zed is embedded within wider discourses of appropriation of resources by the higher classes, which point to BCIL's ambiguous role in promoting sustainable and equitable development within Bangalore.

In ViDA, securitization practices have generated unease among the architects who designed the project because they see them as a violation of the design principles that inspired the project. New built areas disturb the visual appearance of the development, towards more fragmentation, and, they argue, obstruct schemes of natural ventilation and orientation that are supposed to help the house 'breathe'. This is a reflection of the different priorities of architects and residents. For example, in describing the ventilation windows, a resident said, with irony in his tone, that 'those windows are, most of all, to make dust because there is a lot of wind in this area' (interview ViDA R1). While upkeep practices have helped local residents to normalize the housing development within their set of expectations, they challenge the aspirations of those who see themselves as experiment makers and thus contest the need to showcase the experiment as a means to catalyze urban transitions towards low-carbon communities. 
Finally, maintenance, as a resignification of the experiment, is a process that connects experiments into wider circulations of political economy and ecology. In Bangalore, T-Zed has served as a model to justify the adaptation of existing models of development to the moral requirements of the environmentally conscious high classes. The model is successful because it has been replicated by its promoters (BCIL) and because it has helped in the development of a low-carbon industry of consultants, suppliers and designers, which is behind the current policy and commercial push towards solar water collectors and rainwater harvesting in Bangalore.

The case of ViDA is particularly salient in this respect and deserves closer examination. While a field visit to ViDA suggests that the project has been almost forgotten on the ground, the project has become a central part of the national climate change discourse of Mexico, together with a handful of flagship social-housing projects. Policymakers have represented ViDA as a 'best practice' example for Infonavit's nationwide program 'Hipoteca Verde' (Green Mortgage). The Green Mortgage was a top-down response to the demand from Mexican leaders to do something to be shown for Mexico's international commitments to low-carbon policies. It is a provision for an additional amount to supplement existing mortgage packages in Infonavit dedicated to the incorporation of specific 'eco-technologies' (energy- and water-efficient appliances and ceiling insulation) sanctioned by official organisms and guidelines in standard social-housing templates. In 2011, 60\% of Infonavit 480,000 mortgages (with an investment of 44,800 million Mexican pesos) will have a Green Mortgage. Since 2007, when the program started, Infonavit has given 380,000 Green Mortgages and they expect to make the program mandatory within the next few years.

Originally ViDA was conceived as an experimental project financed with conventional Infonavit mortgages and additional support from CONAVI and the Instituto de la Vivienda (to support low-carbon innovation in the design without disturbing existing templates). Infonavit launched the Green Mortgage as ViDA was underway and ViDA promoters saw this new policy as an opportunity to promote their design while incorporating energy- and water-efficient appliances, including low-energy bulbs, a small solar panel for the street lights and water-saving appliances for taps and showers. The appliance requirements of the Green Mortgage were then incorporated into the original design, and prospective owners were offered the Green Mortgage deal. ViDA was, in 2007, one of the first developments in Mexico to obtain a Green Mortgage but, in the overall life of the project, this was a last minute add on, on top of the bioclimatic design that inspired the project. Thanks to a series of expert evaluations and a prize (from the international cement corporation CEMEX), the project ViDA provided an example of how to incorporate low-carbon features without fundamentally changing the work patterns of developers or the relationships between residents, Infonavit and the developers. Moreover, the project ViDA demonstrated how additional capital could be redirected towards the creation of what were described as more sustainable forms of development. Now, ViDA's concerns of adapting developments to the local climate and economic conditions and its focus on how technologies benefit residents has been changed into 'a checklist of minimum technological requirements', as described by a local provider of energy-saving appliances (interview ViDA C4), that the house has to meet to qualify for the increase in the costs allowed by the Green Mortgage.

In that sense, the development has been appropriated at the national level as an example of how 'green building' can be adapted to the existing construction industry (rather than how the construction industry can be adapted to meet new low-carbon global demands). ViDA, together with other projects which also started relatively anonymously and have now become exemplars of green building in Mexico, has also generated new thinking about the potential for poor people to take responsibility for their - yet to occur - carbon emissions in an attempt to bring carbon control mechanisms beyond the realm of middle-class concerns. While in Bangalore T-Zed provided a space to experiment which has allowed the horizontal transmission of knowledge among consultants and service providers, sparkling similar projects at the same scale, in Monterrey, a relatively 
small and obscure example is at the centre of the reconfiguration of housing and infrastructure systems nationally, although the extent to which this is sustainable has to be discussed in the light of social and environmental impacts which the new houses have beyond their locale. Maintaining here has been directed towards reproducing the experimental character of the initiative and creating changes within existing urban regimes.

\section{Conclusions}

The case studies suggest that attempts to 'maintain' climate change experiments are central to their development through time. Following the analysis, maintaining can be understood as emerging from two interrelated processes. First, there is an ongoing process of repair management associated with the making of innovations and uncertain sociotechnical relationships which we have called upkeep. Second, there is a process of careful adjustment to existing urban conditions, physical (in terms of adapting to the specific elements of infrastructure and resources) and semiotic (in terms of developing suitable narratives of change and performance associated with the experiment), which we have called metabolic adjustment. Both processes contain an element of renegotiation of the mechanisms of space and nature production, in turn reconfiguring the realms of responsibility and authority in everyday maintenance, which determine the significance of the experiment for city- and nationwide low-carbon transitions.

The practice of repair is related to the ongoing work required to maintain the experiment 'as an experiment', in terms of sustaining its novel qualities (for example, repairing the different technological innovations in T-Zed) and in terms of normalizing it to ensure that it is an accepted way of life (whether it is redefining some components of the experiment, as in T-Zed, or assimilating them to everyday practices, as in ViDA). Maintenance is therefore needed to balance the novel and the normal within the experiment. While the discursive production of standards and expectations may accelerate this process, the pluricultural character of maintenance and its reliance on the power of things (Graham and Thrift, 2007) means that this is a difficult process that requires taming innovation and renegotiating original ideas, technologies, ecologies and relations in practice within the fabric of the city ( $c f$. Kaika, 2005).

In terms of the process of adjustment, the experiment also requires a series of alternative disconnections, connections and reconfigurations to adjust it to the broader context within which it occurs and to establish its distinctiveness in that setting, whether it is dealing with water scarcity in T-Zed or managing contexts of violence and transforming policy discourses in ViDA. T-Zed and ViDA required specific processes to establish their long-term impact, in the case of T-Zed requiring the private developer to take an unorthodox role and in the case of ViDA hindered by the lack of mechanisms of engagement with local residents. Moreover, both cases signal a process of adjustment to specific neighbourhood conditions in terms of dealing with specific disputes and accommodating the needs of residents in T-Zed, or in terms of changing the designs to adapt to conditions of structural violence in ViDA. Finally, in both cases we observe a renegotiation of arrangements for the production of space and nature. In the case of T-Zed, notions of self-sufficiency are challenged by the reconnections with water resources and with neighbour residents (whether they are in other gated communities or in poor and informal settlements). In the case of ViDA, the role and history of the project have been renegotiated to adapt to the national demands of policymaking in sustainable building. Gaining visibility for infrastructure interventions is a key aspect of experiments. As with the process of normalization, in both cases, maintenance processes purposively seek to distance and distinguish the experiment as novel and to embed it within the existing sociotechnical frame. This balance between distance and embedding seems to be critical to the 'purchase' that the experiment gains in citywide networks 
of urban metabolism. In this way, the findings highlight the important role of infrastructure-based interventions in creating new reconfigurations of urban infrastructure and the maintenance of urban infrastructure regimes (Monstadt, 2009).

While the discourse of securitization is important in both examples, the social dynamics that shape them are very different. T-Zed exemplifies the attempts of elites to achieve urban ecological security (Hodson and Marvin, 2009), while ViDA demonstrates the importance of securing spaces for low-income groups in the context of structural violence. While in T-Zed security maintenance practices are key to ensure the continuity of the experiment and of the capacity of elites to influence the processes of urban reproduction, in ViDA security maintenance practices are directed towards coping with structural violence conditions. Because of the increased complexity and immediacy of maintenance practices (Graham and Thrift, 2007), who benefits from these practices will depend strongly on the context in which they are applied.

The experiments we have discussed here are anything but revolutionary. They do not seek to reconfigure the fundamental relations which structure society - their intention was never so. Nonetheless, we find that they serve as potentially powerful means to create new forms of governing everyday life and city circulations, simultaneously reinforcing and reinventing the landscape of governance. Critically, in giving the experiment its distinctive character and its ordinariness, maintenance is an essential component of how experiments travel. We find that such processes mean that the significance of the experiment does not end with its merging into the local landscape, as it can still be transformed into a symbol or exemplar with wider influence (whether among knowledge communities in Bangalore or at the national level in Mexico).

In conclusion, we find that the emergence of climate change experiments disrupts the sociotechnical system in such a manner that they require a process of 'maintaining' in which relationships around the experiments are redefined. They are embedded in the production of urban space and the transformation of nature as described in the urban political ecology literature. However, the process of 'maintaining' experiments is a precarious one which requires a continuous external input in terms of remaking the experiment (materially and in terms of redefining the narratives which maintain it); and may cause further reconfigurations beyond the experiment in terms of formal and informal institutions and changes in the configurations of responsibility and acceptability. However, this says nothing about the potential spaces for resistance and alternative appropriation of experiments, something which, we believe, is foregrounded in the processes whereby the experiments are lived as an integral part of everyday lives. How climate change experiments are made, maintained and lived is a question to which we intend to pay attention in our ongoing analysis of urban climate change experiments.

Vanesa Castán Broto (v.castanbroto@ucl.ac.uk), Development and Planning Unit, Bartlett Faculty of the Built Environment, University College London, 34 Tavistock Square, London WC1H 9EZ, UK and Harriet Bulkeley (h.a.bulkeley@durham.ac.uk), Geography Department, Durham University, Science Site, South Road, Durham DH1 3LE, UK.

\section{References}

Brand, S. (1994) How buildings learn: what happens after they're built. Penguin, New York.

Bulkeley, H. (2010) Cities and the governing of climate change. Annual Review of Environment and Resources 35.1, 229-53.
Bulkeley, H. and V. Castán Broto (2013) Government by experiment? Global cities and the governing of climate change. Transactions of the Institute of British Geographers 38.3, 361-75.

Castán Broto, V. and H. Bulkeley (2013) A survey of urban climate change 
experiments in 100 cities. Global Environmental Change 23.1, 92-102.

Cooke, J. and R. Lewis (2010) The nature of circulation: the urban political ecology of Chicago's Michigan Avenue Bridge, 1909-1930. Urban Geography 31.3, 348-68.

Desfor, G. and R. Keil (2004) Nature and the city: making environmental policy in Toronto and Los Angeles. University of Arizona Press, Tucson, AZ.

Gandy, M. (2004) Rethinking urban metabolism: water, space and the modern city. City 8.3, 363-79.

Ghosh, A. (2005) Public-private or a private public? Promised partnership of the Bangalore Agenda Task Force. Economic and Political Weekly XL, 4921-2.

Graham, S. and S. Marvin (2001) Splintering urbanism: networked infrastructures, technological mobilities and the urban condition. Routledge, London.

Graham, S. and N.J. Thrift (2007) Out of order - understanding repair and maintenance. Theory, Culture and Society 24.3, 1-25.

Harvey, D. (1996) Justice, nature and the geography of difference. Blackwell, Oxford.

Heynen, N., M. Kaika and E. Swyngedouw (2006) Urban political ecology: politicizing the production of urban natures. In N. Heynen, M. Kaika and E. Swyngedouw (eds.), In the nature of cities: urban political ecology and the politics of urban metabolism, Routledge, London.

Hodson, M. and S. Marvin (2009) Urban ecological security: a new urban paradigm? International Journal of Urban and Regional Research 33.1, 193-215.

Hodson, M. and S. Marvin (2011) Can cities shape socio-technical transitions and how would we know if they were? In $\mathrm{H}$.

Bulkeley, V. Castán Broto, M. Hodson and S. Marvin, Cities and low carbon transitions, Routledge, London.

Hommels, A. (2005) Studying obduracy in the city: toward a productive fusion between technology studies and urban studies. Science, Technology, \& Human Values 30.3, 323-51.

Hommels, A. (2008) Unbuilding cities: obduracy in urban sociotechnical change. MIT Press, Cambridge, MA.
Kaika, M. (2005) City of Flows. Routledge, London.

Keil, R. (2005a) Progress report - urban political ecology. Urban Geography 26.7, 640-51.

Keil, R. (2005b) Social power and the urbanization of water: flows of power. Annals of the Association of American Geographers 95.4, 889-91.

McFarlane, C. (2010) The comparative city: knowledge, learning, urbanism. International Journal of Urban and Regional Research 34.4, 725-42.

Monstadt, J. (2009) Conceptualizing the political ecology of urban infrastructures: insights from technology and urban studies. Environment and Planning A 41.8, 1924-42.

Nair, J. (2000) Singapore is not Bangalore's destiny. Economic and Political Weekly XXXV, 1512-14.

Ranganathan, M., L. Kamath and V. Baindur (2009) Piped water supply to Greater Bangalore: putting the cart before the horse? Economic \& Political Weekly XLIV, 53-62.

Robinson, J. (2006) Ordinary cities: between modernity and development. Routledge, London.

Star, S.L. (1999) The ethnography of infrastructure. American Behavioral Scientist 43.3, 377-91.

Strebel, I. (2011) The living building: towards a geography of maintenance work. Social \& Cultural Geography 12.3, 243-62.

Swyngedouw, E. (2006) Metabolic urbanization: the making of cyborg cities. In N. Heynen, M. Kaika and E. Swyngedouw (eds.), In the nature of cities: urban political ecology and the politics of urban metabolism, Routledge, London.

Swyngedouw, E. and N.C. Heynen (2003) Urban political ecology, justice and the politics of scale. Antipode 35.5, 898-918.

Thrift, N. (2005) But malice aforethought: cities and the natural history of hatred. Transactions of the Institute of British Geographers 30.2, 133-50.

Ward, K. (2006) 'Policies in motion', urban management and state restructuring: the trans-local expansion of business improvement districts. International Journal of Urban and Regional Research 30.1, 54-75. 